\title{
Stage II Renal Pelvis Cancer AJCC v7
}

National Cancer Institute

\section{Source}

National Cancer Institute. Stage II Renal Pelvis Cancer A/CC V7. NCI Thesaurus. Code C6145.

Stage II includes: T2, N0, M0. T2: Tumor invades muscularis. N0: No regional lymph node metastasis. M0: No distant metastasis. (AJCC 7th ed.) 